\title{
Existências temporais e a referência como atravessamento na criação em dança
}

\author{
DANILO SILVEIRA
}

SAYONARA SOUSA PEREIRA

Danilo Silveira é mestrando em Artes Cênicas -USP. Pós-Graduado em Dança - UFBA, 2013. Graduado em dança -Unespar, 2013. Licenciado em Teatro -Uniso, 2008. Cursou dança na Universidade Mayor -Santiago do Chile, 2007-2008. É integrante do LAPETT na ECA-USP. Email: danilosilveira86@gmail.com. ORCID.ORG/00000002-6831-1003

Sayonara Sousa Pereira é professora do PPGAC da ECA-USP. Graduada em Dança -Hochschule Für Musik und Tanz-Alemanha (2003), especialista em Dança - Folkwang Hochschule -Alemanha (1985). Doutora (2007); pós Doutora (2009) pela UNICAMP e (2016) pela Freie Universität Berlin -Alemanha (FU). Dirige o LAPETT na ECAUSP. Email: sayopereira@usp.br 


\section{RESUMO}

O presente artigo se dá a partir das reflexões provenientes da disciplina "Memórias Inscritas no Corpo: Poéticas de Citação e Transmissibilidade", realizada no Programa de Pós-Graduação em Artes Cênicas da Universidade de São Paulo em 2015, almejando uma discussão sobre as referências presentes no processo de criação em dança. Para isso, se busca olhar para o espetáculo "Corpo Desconhecido" da artista curitibana Cinthia Kunifas e através deste olhar, pretendese entender como esse espetáculo pode se tornar uma referência para o também espetáculo de dança "Garoa" (espetáculo vinculado à investigação acadêmica que tem a obra "Corpo Desconhecido" como objeto de pesquisa).

\section{PALAVRAS-CAVE}

Referência, atualização, memória.

\section{ABSTRACT}

This article starts from the reflections from the discipline "Inscribed Memories Body: Poetics of Quotation and Transferability", held in the Graduate Program in Performing Arts at the University of São Paulo in 2015, wishing a discussion of the references present in the creation in dance. For this, we seek to look at the spectacle "Body Unknown" of artist Cinthia Kunifas, from Curitiba, and through this look, we intend to understand how this spectacle can become a reference for also dance spectacle "Drizzle" (spectacle linked to academic research that has the work "Body unknown " as the search subject).

\section{KEYWORDS}

Reference, update, memory.

\section{Introdução}

Ano de 2003. Em cena um corpo está em pausa. Uma pausa permanente, insistente. Pausa? Esta ação de "pausa" vai além da nudez do olhar, no lado invisível da intensão. Decisões são tomadas e organizações naturais do corpo são postas em questão. Simplesmente as ações também pausam permitindo que outras ações existam. Pisca-se pouco os olhos, quase não se engole a saliva, não se respira de forma cotidiana. Ouvem-se cada vez mais os espaços vazios do corpo, um corpo que se apresenta como desconhecido. Assim, micro ações são percebidas e o tempo é dilatado, re-significado. Um tempo que transcende a existência cronológica. O corpo apenas existe nesta proposição.

À medida que a ação protagoniza-se como presença, se dá o processo de mutação. O processo é lento e cuidadoso. O corpo que se desconhece torna-se diferente. Derrete? Destrói? Constrói? Ou será tudo isso ao mesmo tempo? A ação dura, perdura, insiste. Permanece por trinta minutos, ou mais. Na verdade, muito mais. Permanece por treze anos. Estamos aqui falando de "Corpo Desconhecido", espetáculo de dança da artista curitibana Cinthia Kunifas. 
Ano de 2011. Em cena um corpo está em pausa. Uma pausa que aos poucos se transforma em vibração. A vibração cresce e se espalha pelos ossos, músculos, pele e poros. Uma vibração que toma conta da existência cênica. A vibração se transforma. Saltos agora predominam. Saltos que deixam acontecer. Decisões são tomadas e organizações naturais do corpo que salta são postas em questão. As ações entram em contato com o espaço. Os saltos viajam pela sala de apresentação. A respiração existe de forma ofegante. Insiste-se na ação de saltar. Micro e macro ações são percebidas. O invisível agora escapa a vista humana, tornando-se uma possibilidade interior ao visível. A ação permanece por vinte minutos, ou mais. $\mathrm{Na}$ verdade, um pouco mais. Permanece por quatro anos. E após permanecer encontra outro modo de olhar para esses acontecimentos. Estamos aqui falando de "Invisível", espetáculo criado e dançado por um artista crescido na cidade de Araçoiaba da Serra, interior do estado de São Paulo.

"Invisível", como dito, se configurou em uma nova proposição. Agora, em 2016, o título é "Garoa". Não mais estão os saltos e sim existências espaciais, e/ou insistências temporais. No entanto, algo ainda permanece: o desejo de entender o tempo das coisas.

A pretensão deste trabalho não é de forma alguma comparar o processo de criação de "Garoa" com o processo de Cinthia Kunifas, mas começar a entender como que a obra de Kunifas se torna uma referência para o processo de "Garoa" e como que a partir deste entendimento de "referência", a pesquisa de mestrado é resignificada e atravessada por uma prática artística. E como que esta prática artística contribui para a pesquisa com um olhar de quem está artisticamente interessado na questão do tempo de existência das coisas.

Deste modo, aqui se intenta compartilhar um breve percurso que discorre sobre o trajeto reflexivo da investigação que vem sendo desenvolvida no Programa de Pós-Graduação e Artes Cênicas da Universidade de São Paulo - USP. A pesquisa intitulada "Criação em Dança: existindo em permanência", se dá a partir da reflexão sobre a criação em dança propondo olhar para a obra "Corpo Desconhecido" da artista Cinthia Kunifas, pretendendo criar uma reflexão sobre um processo de criação que se reconhece em permanência ${ }^{1}$, ou seja, em continuidade por meio da atualização/percepção do mesmo. Paralelamente à pesquisa acadêmica, se desenvolve atualmente uma investigação artística que existe desde março de 2014 e que parte de duas palavras-chave tiradas da pesquisa de mestrado. São elas: atualização e insistência. Assim, essas palavras-chave tornaram-se mote de provocação e manutenção para a criação artística que, por hora, está sendo chamada de "Garoa"'.

A partir da vivência na disciplina "Memórias Inscritas no Corpo: Poéticas de Citação e Transmissibilidade", realizada em 2015 no Programa de Pós-Graduação em Artes Cênicas da Universidade de São Paulo, sob a coordenação da Profa Dra Andréia Vieira Abdelnur Camargo e Profa Dra Sayonara Pereira, se almeja com este

\footnotetext{
$\overline{1}$ A referência conceitual permanência é estudada nos processos de comunicação. Em dança este conceito é trazido por Machado (2001), que busca entender a permanência como um fenômeno evolutivo. Machado (2001) discute permanência como continuidade e não como estagnação. Segundo Machado, permanência é movimento, se distinguindo de equilíbrio; não há como permanecer e manter-se igual. Permanência acontece porque há mudança.

${ }^{2}$ Essa investigação artística foi aprovada pelo edital Proac 20/2014 Primeiras Obras de Produção de Espetáculo de Dança. Garoa conta com a colaboração artística de Andréia Nhur, Gladis Tridapalli e Paola Bertolini 
artigo refletir sobre como se dá o processo de referenciação artística. Assim, se busca identificar de que maneira as questões existentes na pesquisa acadêmica que está sendo desenvolvida no Programa de Pós-Graduação em Artes Cênicas da USP podem se tornar uma citação para a investigação artística - solo de dança -. Deste modo, a questão que queremos ressaltar é a presença de referências e citabilidades em processos criativos em dança.

Para a construção desta discussão aqui apresentada, a proposta é trazer a investigação artística do solo de dança "Garoa" como objeto relacional sobre as questões vivenciadas na disciplina. É através de "Garoa" que agora se tenta olhar para o que existe na pesquisa que estamos desenvolvendo através de atravessamentos significativos e assim perceber, como essa relação é construída por um corpo que vive e reflete sobre sua memória criativa.

\section{O corpo em "Corpo Desconhecido"}

Bailarina e Mestre em artes cênicas pela Universidade Federal da Bahia, Cinthia Kunifas nasceu em Curitiba (PR), em 1969. Bacharelou-se e licenciou-se em dança na Pontifícia Universidade Católica do Paraná (PUC/PR) e especializou-se em consciência corporal-dança na Faculdade de Artes do Paraná. Recebeu bolsa de estudos para o American Dance Festival em Durham, na Carolina do Norte, nos Estados Unidos, participando de oficinas e performances. Em Curitiba, Kunifas trabaIhou como diretora e coreógrafa da Companhia da Cidade entre 1996 e 1997, e atualmente é professora dos cursos de dança e teatro da Faculdade de Artes do Paraná desde 1995. Em 2002 Cinthia Kunifas deu início ao processo de criação do espetáculo de dança "Corpo Desconhecido".

A obra "Corpo Desconhecido" veio de um processo criativo que durou mais de uma década, e partiu de uma inquietação sobre a reflexão de um corpo em crise que buscou construir um vocabulário cuja fonte foi o próprio corpo. Assim, a trajetória de uma vida inteira esteve inscrita nesse corpo, inserido num fluxo de transformação em que a dança se realizou no trânsito entre ele e o ambiente. Os micro movimentos foram explorados com cuidado e o espetáculo, desta forma, estudou as sensações e as mudanças de estados do corpo. As questões, que neste espetáculo foram construídas, existiram de maneira particular e tiveram a ver com o modo de operação da artista intérprete criadora. Com tal característica, essas questões se mesclaram em seu modo operativo proveniente de uma trajetória artística que lidou com um fazer e um olhar o seu processo de criação durante o tempo em que ele existiu.

"Corpo Desconhecido" já viveu outras temporalidades e formas outras de entendimento da questão que o norteia. Conquanto, mesmo com muitas formas de organização, para fazer-se vivo o espetáculo existiu permanecendo em um mesmo modo de se fazer essa dança, em uma mesma configuração cênica. Sobre seu processo criativo Cinthia Kunifas (2008, p. 107) alega que "embora o processo de reintegração tivesse se iniciado anos antes da criação de 'Corpo Desconhecido', como todo processo foi necessário tempo para que os padrões fixados pudessem ser alterados". Desta forma, é importante ter ciência de que a própria obra foi sendo repercebida e re-significada durante sua criação, tendo o tempo como fator importante para a existência do trabalho. 
O processo de criação em dança é um acontecimento que pode estar constituído de elementos intuitivos, poéticos concretos e/ou não concretos. Para Kunifas, o artista é o ser que está em constante transformação nas suas interações com o mundo e por isso, ser artista é fazer parte de um processo histórico. Tendo isso em vista, Kunifas alega que "Corpo Desconhecido" é um processo que não parte do nada, esta investigação artística depende de existências históricas prévias que se inscrevem em seu corpo como referências. Para a investigação e criação deste espetáculo a artista dialoga com outros entendimentos sobre a criação em dança, sofrendo, principalmente, influências do pensamento oriental, sobretudo do Butô. Segundo Kunifas (2008, p. 29), "o corpo, no Butô, está eternamente em crise de identidade, não se distinguindo do lugar onde se encontra e sendo sempre um processo, inacabado e perecível". Ao criar "Corpo Desconhecido", Kunifas esteve, então, em contato referencial com a ideia de "corpo morto". Para Kunifas, baseada nos dizeres de Rodrigues (1999) o termo "morto" se distancia da acepção que normalmente se atribui a ele. Este termo se apresenta uma vez que se coloca como receptáculo do ambiente que o circunda.

O corpo morto do Butoh [...] é um corpo em perene estado de transformação, um corpo aberto e incompleto e que se refaz a cada performance sem, no entanto, completar-se. Estão ali presentes não só a expressão da contemporaneidade do homem japonês, mas também a sua verdade arcaica e seus questionamentos mais profundos (RODRIGUES, 1999, p. 51).

Assim, em seu processo de criação, Kunifas entende que o corpo não busca expressar uma ideia, mas a si próprio, fazendo cada vez menos, diluindo-se cada vez mais com o que está fora dele. A partir de suas referências, "Corpo Desconhecido" lidou então com um corpo em crise, um corpo que constrói uma dança de caráter orgânico e subjetivo. Segundo Kunifas, "Corpo Desconhecido" não apresenta uma estática oriental, mas seguramente toca-a em pontos cruciais.

Deste modo, uma forte referência do Butô para "Corpo Desconhecido" é Hijikata e sua noção de corpo em constante transformação. Tatsumi Hijikata (19281986) considerado o criador da dança-teatro Butô, inicialmente chamado de Ankoku Butoh, desenvolveu e apresentou trabalhos performáticos em locais da periferia japonesa. Estes trabalhos questionavam a invasão cultural ocidental que o Japão sofria na época. Em 1959, Hijikata apresentou a performance "Kinjiki" ("Cores Proibidas"). Concebida a partir do romance homônimo de Mishima Yukio e outros escritos de Jean Genet, esta obra foi coreografada e interpretada por ele e por Yoshito Ohno, filho de Kazuo Ohno. No entanto, apenas anos mais tarde a obra foi considerada um marco inaugural do movimento Ankoku Butoh, ou "dança das trevas". Para Kunifas, baseando-se em Christine Greiner (2013), o intuito de Hijikata não era propor novidades ou mesmo negar o passado, mas sim tentava explorar a consciência e o corpo em sua plenitude. 
Para entender este paradoxo é importante saber que Hijikata não buscava "vocabulários" ou passos de dança. Nem parecia contrapor-se ou aliar-se a esta ou aquela estética já estabelecida. (...). As suas questões eram de outra natureza e diziam respeito, antes de mais nada, ao colapso do corpo, à exploração da consciência (e do inconsciente cognitivo), ao enfrentamento da morte e à investigação de campos de percepção ainda não suficientemente pesquisados. (GREINER, 2013, p. 02)

Assim, a dança de Hijikata se preocupava mais com a investigação corporal do que com questões narrativas. O Butô de Hijikata formulou não só uma perspectiva de corpo em decomposição e constante transformação, como também vislumbrou uma dança alimentada pelas memórias da carne. Portanto, a referência de Hijikata, bem como de outros artistas orientais como Kazuo Ohno, por exemplo, trouxeram o prisma da transformação para o entendimento do corpo na dança de Kunifas, através de investigações e práticas de algumas técnicas orientais. Assim sendo, o corpo em "Corpo Desconhecido", mesmo sendo um corpo ocidental, possui familiaridades com o pensamento Butô, e por isso se apresenta como um processo em constante mudança, como um corpo incompleto.

\section{A referência temporal como atravessamento}

Como vimos, no processo de criação do espetáculo "Corpo Desconhecido", a relação com o tempo foi um fator crucial para que a obra fosse sendo configurada. Sobre o tempo de criação deste espetáculo, Cinthia Kunifas (2008, p.107) diz que "a integração entre meu corpo e seu entorno, entre meu cotidiano e minha arte foi acontecendo ao longo do tempo, tendo se consolidado com o processo de criação de 'Corpo Desconhecido'”. Para Kunifas (2008) a interação e integração com seu processo criativo acontecem sim no tempo de existência da criação, a partir de um diálogo constante entre sua metodologia e suas referências que se configuram de maneira permanente, construindo momentos que vão sendo atualizados na medida em que a obra entra no tempo de percepção da mesma. No espetáculo de dança "Garoa", que provém de "Invisível", a discussão sobre o tempo sempre esteve presente e uma pergunta que perdura é: qual o necessário tempo existente de cada acontecimento? É preciso que ele exista em dilatação para se apresentar como significado? Os acontecimentos que existem nesse espetáculo entram e saem de uma lógica que não é apenas visual, mas sensitiva. Por isso, percebeu-se, em "Garoa”, que não necessariamente o tempo dilatado é a principal discussão apresentada, mas sim o tempo que leva para que o processo seja percebido e tateado.

Nem "Invisível" e nem "Garoa" foram criados a partir de "Corpo Desconhecido". Mas ao falar de tempo nestes trabalhos, se observa não apenas um mesmo interesse estético com a obra de Kunifas, o interesse se expande para um fator consequente que é o ato metodológico e criativo. Por isso, já que o espetáculo "Corpo Desconhecido" tem o tempo como fator importante para a criação e percepção, de igual modo no espetáculo "Garoa", a pergunta que se apresenta é: como se pode propiciar um atravessamento relacional entre os dois processos 
criativos? Pode-se, aqui, entender que "Corpo Desconhecido" se torna sim uma referência para "Garoa". Deste modo, quando e como a referência artística pode de fato se tornar uma interferência para o meu processo artístico? Neste caso, é possível que isso aconteça?

Isabelle Launay (2009) apresenta como proposta olhar para a memória como uma re-invenção do passado no presente de maneira não cronolimitada, não se apegando na forma linear de tratar o relato histórico. Launay (2009, p. 89) convida a olhar para uma história que pode ser construída por "um emaranhado de experiências sinestésicas, de imaginários corporais, de espaços inventados, de temporalidades múltiplas que geram a transformação ininterrupta que cada obra realiza a partir de outras". Desta forma, paremos e pensemos na palavra atravessamento, refletindo sobre o atravessamento como um jogo de vai e vem não linear, não representativo, como uma busca de referência que se re-significa com o olhar. Ou seja, "Corpo Desconhecido" pode se tornar referência para "Garoa" à medida em que, ao vivenciar o próprio processo como atravessamento, o artista reflete sobre sua pesquisa a partir das questões habitadas por suas referências.

Para Launay (2009, p. 90), "existem múltiplas formas de se trabalhar com a memória de um gesto para que uma experiência corporal se conte, se transforme, se estabilize, se contamine e se dissemine". Na relação criada entre "Corpo Desconhecido" e "Garoa", não existe necessariamente uma transmissão gestual reconhecida. O que existe é uma aproximação contextual, ou talvez até mesmo estética, pautado no contexto histórico referencial em que ambas as obras estão inseridas. Assim, ao olhar para "Corpo Desconhecido" torna-se impossível ignorar os interesses em comum nas duas obras ("Corpo Desconhecido" e "Garoa"). Pode ser que o artista investigador que se permite sentir-se provocado por sua obra de referência gere relações diretas com sua própria criação. Desta forma, podemos pensar que essa provocação pode ser considerada como memória coreográfica?

O interesse de um olhar sobre o que se chamará provisoriamente de 'intergesto' é imenso para a memória coreográfica. Quando a dança se imagina em uma relação com o mundo, se imagina também numa relação com ela mesma. A presença de uma dança anterior em outra dança, mesmo se ela resultar de uma citação, de um plágio, de uma alusão, de uma paródia, de um pastiche ou de uma encenação burlesca, provoca reflexão sobre a memória que a dança tem de si mesma. (LAUNAY 2009. P. 91)

Assim, a referência de "Corpo Desconhecido" vem re-significar a experiência vivida em "Garoa". Olhando para a história que une os dois trabalhos e gerando não apenas um assunto em comum, mas o que se tenta traduzir aqui como atravessamento. Ou seja, o atravessamento pode vir a ser esse olhar contaminado e diferenciado para não, apenas, entender de onde se vem e para onde se vai, mas também poder discutir o assunto a partir da experiência criativa, a partir de um corpo que dança os interesses que são próximos ao seu objeto de estudo. Sobre a citação que é realizada na dança, Launay (2009. P. 92) diz que: "o desafio não tem a ver com uma história das fontes de tal ou tal obra (...). O desafio está muito mais em 
revelar como uma obra moderna inventa sua própria origem/originalidade, (...) isto é, seu incessante diálogo com sua própria história". Por conseguinte, observar e entender o seu trajeto histórico, pode gerar um olhar reflexivo sobre o assunto que se pretende discutir. Permitindo-se contaminar, tendo o olhar, não de dentro, mas um olhar aproximado e relativizado.

O modo operativo do artista, desta forma, pode entrar em contato com seu histórico e a partir deste ponto de vista, refletir sobre o mesmo. Pensar sobre a relação entre o artista e sua referência pode parecer um modo bastante interessante de estar atualizando sua memória. Assim, a memória pode se apresentar não como um resgate ou projeção de algo ou alguém, mas sim como re-significação e percepção de seu processo criativo.

Sobre a memória nos processos criativos Pereira (2011, p. 04) diz que "o pretérito é revisitado, reestudado, e trazido inicialmente em forma de memória inscrita no corpo, e poderá reverberar na cena". Segundo Pereira (2011, p. 04) "a atuação se atualiza, encontra outros acentos e tem a possibilidade de impactar novamente tanto o corpo que reaprende a obra, quanto ao público que tem a chance de assistir ao vivo uma lembrança reinaugurada". A memória, logo, pode ser então um processo de seleção do que se torna, para o artista, referência. De igual modo, o interesse aqui está em olhar para o processo de criação como algo que se mantém à medida que o mesmo vai se tateando e identificando as questões - assunto, pensamentos, estética, histórico e memória - que nele sobrevivem. Identificando e entrando em contato com suas referências.

Giorgio Agambem (2009), nos lança a questão: de quem e do que somos contemporâneos? Pensar sobre essa questão nos remete ao atravessamento proposto aqui, e em como de fato deixamos nossas referências colorir nosso olhar para a discussão. Para Agambem (2009) ser contemporâneo é viver o seu tempo, mergulhando nas trevas, tateando o escuro. A criação, então, pode se desenvolver no tempo de constatações e relações com suas referências, podendo ser resultado de ações existentes além do próprio processo. A criação, desta forma, é um processo de correspondência. Se para Launay (2009. P. 90), "a dança é uma arte 'viva'”, que o que existiu ainda está se reconfigurando a partir do que acontece no presente, e se a “'transmissão' da dança não existe”, pois ela só ocorre por transformações, podemos pensar que a re-significação de nossas referências estão o tempo todo em ação. E estar em re-significação é estar em atualização.

\section{Considerações finais}

Ao fechar os olhos podemos retornar a tempos outrora vividos, sentir perfumes, ouvir estalos e sussurros outrora saboreados. Assim, a memória não é algo que está no passado. Memória é presença re-significada. É uma referência vivenciada que hoje podemos transformá-la em um contexto poético. Se tornando atravessamento de questões.

Por fim, parece que o atravessamento consiste na relação. A atualização, logo, não se resume apenas a dar vida a alguma coisa, mas sim olhar para o que acontece e, principalmente, para como o que está acontecendo gera relação com o processo e contribui para o mesmo. Percebemos que o processo de criação de "Corpo Desconhecido", se dá por conta da atualização das informações presentes 
no próprio processo, fazendo com que este se apresentasse como uma continuidade, apresentando-se uma existência permanente.

O interesse deste artigo esteve em olhar para o processo de criação que se deixa atravessar por suas referências e assim construir um olhar afetado pela experiência. Kunifas em "Corpo Desconhecido" lida com o que acontece ao permanecer; permanecer por anos em uma questão. Permanecer para gerar mudança e/ou gerar mudança porque se precisou permanecer. "Garoa", que pode ser entendido como um processo recém-nascido se espelha na questão do "tempo" e após olhar para o processo de criação de Kunifas a pesquisa acadêmica se atenta ao que está em evidência nas lógicas de manutenção artística e, como resultado, se encontra com a questão trazida neste trabalho, que é: qual o necessário tempo das coisas? $\mathrm{Na}$ obra de Kunifas vemos que a permanência pode estar relacionada ao processo perceptivo. Por isso, esta pesquisa vem do interesse em discutir a criação em dança que sobrevive se reinventando, não se prendendo ao rígido, tornando-se possível a olhares e sabores; atualizando-se à beira do não dizível, do não sabível, e por fim, do desconhecido.
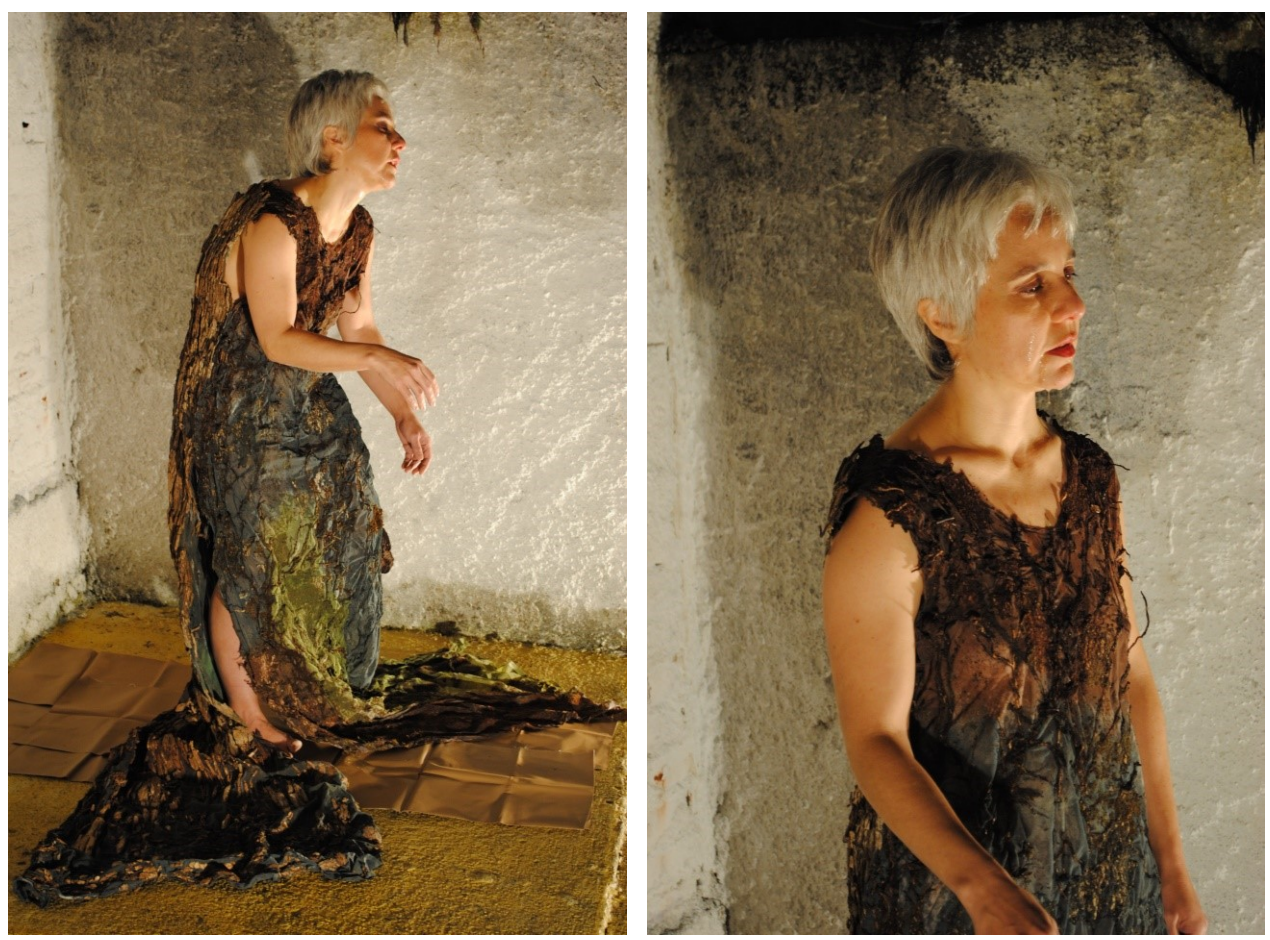

Figuras 1 e 2. Apresentação do espetáculo "Corpo Desconhecido", agosto de 2012. Fotografias do arquivo do espaço de arte Tardanza. 

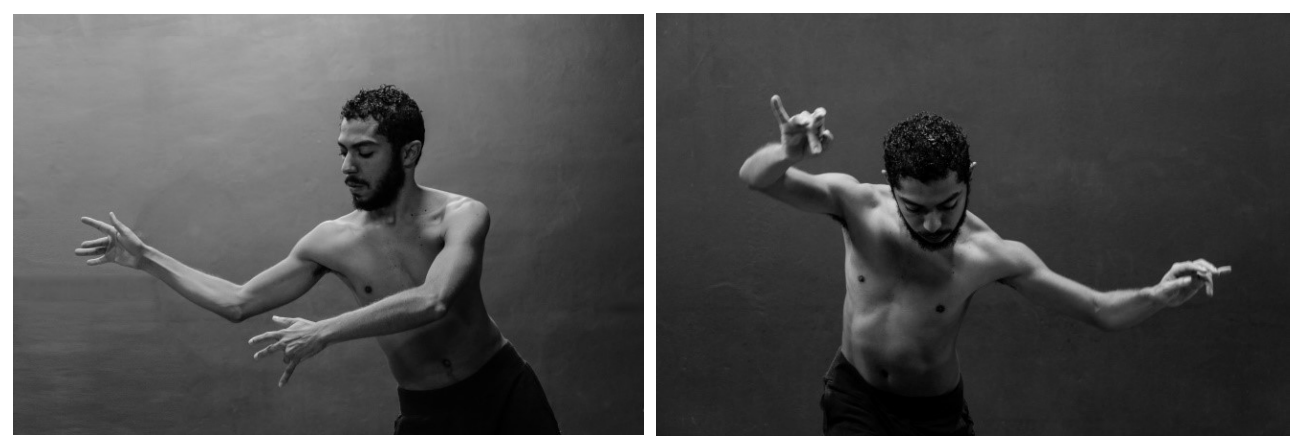

Figuras 3 e 4. Apresentação do espetáculo "Garoa", agosto de 2015. Fotografias de Cris Almeida

\section{Referências}

AGAMBEM, Giorgio. O que é o contemporâneo? E outros ensaios. Chapecó: Argos Editora da Unochapecó, 2009.

CORPO Desconhecido. Vinicius Nisi. Curitiba - PR. 30:42 min. 2014.

Disponível em: <https://www.youtube.com/watch?v=0LflhQ89iUM> Acesso: 11 ago. 2016

GREINER, Christine. O colapso do corpo a partir do ankoku butô de Hijikata Tatsumi - disponível: <http://www.japonartesescenicas.org/estudiosjaponeses/articulos/ankokubutoh.pdf> Acesso: 10 de abril de 2013

KUNIFAS, Cithia Bruck. Corpo desconhecido: um contínuo processo de criação em dança. Salvador, 2008. Dissertação (Mestrado em Artes Cênicas) - Universidade Federal da Bahia, 2008.

LAUNAY, Isabelle. A elaboração da memória na dança contemporânea e a arte da citação. Bienal SESC de Dança, 2009.

MACHADO, Adriana B. A natureza da permanência: processos comunicativos complexos e a dança. São Paulo, 2001. Dissertação (Mestrado em Comunicação e Semiótica) - PUC-SP, 2001.

PEREIRA, Sayonara. Corpos que esboçam memórias - Anais do 2 o encontro nacional de pesquisadores em dança - ANDA - Dança: contrações epistêmicas 2011.

RODRIGUES, Eliana. Corpo em transformação: entre o grotesco e o Mimético. In:

Cadernos do GIPE-CIT, Salvador, n. 7, nov. 1999. p. 41-54.

SUJEITOS Dançantes com Cinthia Kunifas. Gladis Tridapalli. Curitiba - SP. 12:38 min. 2013

Disponível em: <https://www.youtube.com/watch?v=pluYXZEb-v4> Acesso: 11 ago. 2016

Recebido em 15/08/2016 - Aprovado em 12/07/2017 